\title{
Stabilization of Photosensitive Curcumin by Microencapsulation ${ }^{\dagger}$
}

\author{
Diana-Ioana Buliga, Aurel Diacon, Ioana Asofiei and Cristian Boscornea * \\ Faculty of Applied Chemistry and Materials Science, University POLITEHNICA of Bucharest, 1-7 Gheorghe \\ Polizu st., 011061 Bucharest, Romania; dianaioana.buliga@yahoo.com (D.-I.B.); aurel.diacon@upb.ro (A.D.) \\ asofiei.ioana@yahoo.com (I.A.) \\ * Correspondence: cristian.boscornea@upb.ro \\ † Presented at the 16th International Symposium "Priorities of Chemistry for a Sustainable Development" \\ PRIOCHEM, Bucharest, Romania, 28-30 October 2020.
}

Published: 18 November 2020

Keywords: curcumin; encapsulation; photocatalyst; $\mathrm{TiO}_{2}$

The natural dyes extracted from plants are efficient sensitizers for $\mathrm{TiO}_{2}$ particles involved in photocatalytic processes. Curcumin, extracted from turmeric powder, presents an intense sensitizing effect, leading to very good efficiencies of $\mathrm{TiO}_{2}$ in the degradation processes of contaminants $[1,2]$. One of the important issues that have to be solved is the photochemical degradation of the sensitizer, which results in loss of the catalysts efficiency over time. Experimental data regarding the photochemical stabilization by encapsulation of curcumin used as sensitizer in photocatalytic processes are presented.

For the extraction of curcumin, both conventional and microwave-assisted methods were used. The extraction was optimized by analyzing the influence of the main parameters. The encapsulation via silanization $[3,4]$ was performed using tetraethoxysilane (TEOS) and 3-aminopropyltriethoxysilane (APTES) or lysine, which can successfully interact with the carbonyl groups of curcumin. The photodegradability of the stabilized curcumin was studied, which showed an increase of $40 \%$ for light stability after its encapsulation in a silica matrix. The studies regarding the optimal parameters showed that the extraction of curcumin is more efficient when increasing the temperature: the absorption maximum was double for ethanol reflux extraction compared to maceration. For the microwave-assisted extraction (MAE), the optimal parameters are: $60{ }^{\circ} \mathrm{C}, 15 \mathrm{~min}$, and $900 \mathrm{rpm}$. Analyzing the required extraction time and the corresponding energy consumption, MAE proves to be a more efficient extraction method.

Curcumin encapsulation leads to the formation of nanometric spherical capsules with porous morphology (Figure 1). The process is influenced by the electrostatic interaction between TEOS and the amino group of the surfactant, as well as by the working conditions. According to the quantity of curcumin encapsulated in a gram of silica, it can be stated that a very good dispersion of the dye is achieved.

Natural dyes represent a viable alternative for $\mathrm{TiO}_{2}$ sensitizing in photocatalytic processes. Encapsulation can be an efficient strategy regarding the increase in the stability of natural dyes during photodegradability processes. 


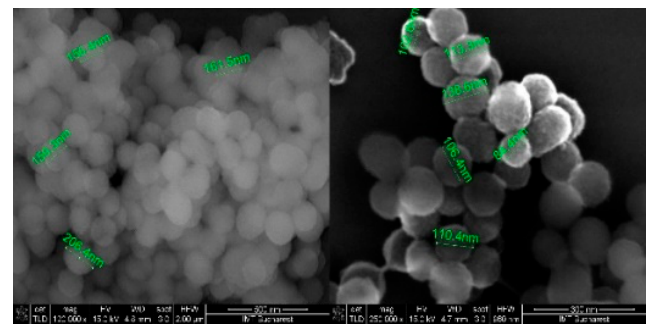

Figure 1. SEM analysis of encapsulated curcumin.

Acknowledgments: This work was supported by a grant of the Romanian Ministry of Research and Innovation, CCCDI-UEFISCDI, project number PN-III-P1_PCCDI-2017-0428/ 40-PCCDI-Polymer based innovative nanotechnologies for new advanced materials-NAPOLI 19 “-component 4- Innovative Hybrid Materials with Photocatalytic Properties", within PNCDI III.

\section{References}

1. Gusiak, N.B.; Kobasa, I.M.; Kurek, S.S. Nature inspired dyes for the sensitization of titanium dioxide photocatalyst. CHEMIK 2013, 67, 1191-1198.

2. Lim, J.; Bokare, A.D.; Choi, W. Visible light sensitization of $\mathrm{TiO}_{2}$ nanoparticles by a dietary pigment, curcumin, for environmental photochemical transformations. RSC Adv. 2017, 7, 32488-32496.

3. Jaffar, H.I.; Hussein, S.I. Preparation and some characterization of curcumin-silica materials by sol-gel method. IJARSET 2015, 6, 1153-1160.

4. Banerjee, C.; Maiti, S.; Mustafi, M.; Kuchlyan, J.; Banik, D.; Kundu, N.; Dhara, D.; Sarkar, N. Effect of encapsulation of curcumin in polymeric nanoparticles: How efficient to control ESIPT process? Langmuir 2014, 30, 10834-10844.

Publisher's Note: MDPI stays neutral with regard to jurisdictional claims in published maps and institutional affiliations.

(C) 2020 by the authors. Licensee MDPI, Basel, Switzerland. This article is an open access article distributed under the terms and conditions of the Creative Commons Attribution (CC BY) license (http://creativecommons.org/licenses/by/4.0/). 